\title{
Analysis of the Spatio-temporal Patterns of Dry and Wet Conditions in the Huai
}

\section{River Basin Using the Standardized Precipitation Index}

\author{
Yi He ${ }^{\mathrm{a}}$, Jinyin $\mathrm{Ye}^{\mathrm{b}}$, Xiaoying Yang ${ }^{\mathrm{c}, *}$
}

${ }^{a}$ Tyndall Centre for Climate Change Research, School of Environmental Sciences, University of East Anglia, Norwich, United Kingdom.

${ }^{\mathrm{b}}$ Anhui Province Meteorological Observatory, Hefei, China.

${ }^{c}$ Department of Environmental Science and Engineering, Fudan University, Shanghai, 200433, China. Email: xiaoying@ fudan.edu.cn. Phone: 0086-21-65642192.

\section{Abstract}

Located in a transition zone between the northern and southern climates in China, the Huai River Basin is prone to extreme events such as drought and flood. Based on the daily precipitation data at 134 stations between 1961 and 2013, this paper analyzed the spatial and temporal patterns of the dry and wet conditions in the Huai River Basin through the statistical analysis of the rainfall stations' annual and seasonal standard precipitation index (SPI) series. Annual SPI series exhibited a decreasing trend at 86 stations and an increasing trend at the remaining stations. None of the increasing trend was significant, while the decreasing trend was significant at two stations at $5 \%$ significance level $(\alpha=0.05)$ and one station at $10 \%$ level. Seasonal-wise, there has been a prevailing trend of drying in spring and autumn, and wetting in summer and winter. The trends in the spring and summer SPI series have been mostly insignificant, while those in autumn and winter significant $(\alpha=0.10)$ at over 30 stations. The Pettitt test results indicated that the significant transitions $(\alpha=0.10)$ in the autumn and winter SPI series mostly occurred in the middle to late 1980's. Comparison of the average number of dry and wet years between the two sub-periods of 1961-1984 and 1990-2013 suggested a significant increase $(\alpha=0.05)$ in the average number of severely wet years across much of the basin. Overall, significant changes have already occurred in the dry and wet conditions of the Huai River Basin, which could have profound impacts on the food and water safety situation of the region.

\section{Keywords}

Standard Precipitation Index; trend analysis; change point detection; extreme event; Huai River Basin

\section{Introduction}

Under the background of global climate change, the occurrence frequency, 
amplitude, and impacts of extreme events, such as heavy rain, flood, and drought, have exhibited an increasing trend (Parry et al., 2007). The close linkage between climate and hydrological cycle renders the necessity of studying the changes in hydrological processes around the world. Knowledge of the spatial and temporal characteristics of the hydro-climatological phenomenon and detecting their patterns of change is indispensable to the sustainable management of water resources and adaptation to climate change in a given region (Oguntunde et al., 2011). Precipitation is one of the most important factors influencing the dynamics of water systems in a given region. Due to the considerable variability in precipitation over both space and time, sometimes even at small scales, it is particularly difficult to detect its spatio-temporal patterns of change (Shi et al., 2013).

In the past decades, a number of indices have been developed for detecting and monitoring drought, whose advantages and drawbacks under different conditions have been comprehensively reviewed by Mishra and Singh (2011). Compared to other indices, the standardized precipitation index (SPI) proposed by McKee et al. (1993) has several advantages including the flexibility of time scale, the stability of the spatial structure, the requirement of fewer input variables, and the simplicity of calculation (Bazrafshan et al., 2014). So far, the SPI has been widely applied in drought assessment, monitoring, and forecast globally (Spinoni et al., 2014) and in many regions such as Africa (Cheo et al., 2013; Dutra et al., 2013), China (Feng et al., 2013; Liu et al., 2012; Zhang et al., 2012), Greece (Karavitis et al., 2012), India (Dhakar et al., 2013; Ganguli and Reddy 2014), Iran (Tabari et al., 2012), Italy (Di Lena et al., 2014), Malaysia (Zin et al., 2013), Pakistan (Xie et al., 2013), Serbia (Gocic and Trajkovic, 2013), and United States (Ford and Labosier, 2014).

Although originally developed for drought detection and monitoring, the SPI can be applied to reveal wetter than normal conditions. For example, Zhang et al. (2009), Du et al. (2013), Fischer et al. (2013), and Huang et al. (2014) used the SPI to investigate the spatiotemporal variation of dry/wet conditions and their annual/seasonal trends in the Pearl River basin, Hunan Province, Xijiang River basin, and Sichuan Province of China, respectively. Raziei et al. (2012) investigated the spatio-temporal variability of winter dry/wet events through the 1-month SPI. Tosic and Unkasevic (2014) analyzed the wet and dry periods in Serbia using the 1, 3, 6 and 12-month SPI. In conjunction with the SPI, statistical methods such as the Mann-Kendall (M-K) test, the principal component analysis (PCA), and the wavelet transform analysis were then applied to analyze the 
temporal and spatial variabilities in dry and/or wet conditions (Gocic and Trajkovic, 2014; Li et al., 2013; Zhao et al., 2012).

China's climate is influenced by complex atmospheric circulation regimes that result in diverse precipitation patterns. Due to its rapid development and population growth, it is also faced with higher risk of extreme events such as drought and flood than many other parts of the world (Fischer et al., 2013). The Huai River Basin is selected in this study because it encompasses one of the fastest growing economic regions in China but is highly vulnerable to extreme hydrometeorological events (Ye et al. 2014). Situated in a transition zone between the northern and southern climates in China, the Huai River Basin is characterized by the warm temperate monsoon climate in the north and the subtropical climate in the south. Its average annual precipitation is around $850 \mathrm{~mm}$, which generally decreases from south to north. With 50 to $75 \%$ of its annual rainfall concentrated in a few months of the flooding season, there are large inter-annual variations in precipitation in the basin, which makes it prone to both flood and drought. Between 1470 and 2010, it was estimated that there had been 63 extreme floods and 46 extreme droughts in the Huai River Basin (Wu et al., 2011).

There have been a number of studies on the spatio-temporal characteristics of precipitation in the Huai River Basin or its sub-basins. Du et al. (2014) analyzed the spatio-temporal characteristics of extreme precipitation events in the Huai River Basin at 30 stations during 1960-2011. They found that annual maximum precipitation showed an increasing trend at 20 stations and a decreasing trend at 10 stations without any being significant $(\alpha=0.05)$. Shi et al. (2014) analyzed the spatio-temporal patterns of precipitation concentration indices in the upstream Shaying River sub-basin based on daily precipitation observations at 38 stations from 1951 to 2010. They found a positive trend in the precipitation concentration index at most stations, but none of trends was statistically significant $(\alpha=0.10)$. Xia et al. (2012) analyzed the spatio-temporal trend of extreme precipitation events in the Huai River basin based on the daily precipitation data of 27 stations from 1960 to 2009, and they detected an insignificant ( $\alpha=0.05$ ) positive trend in annual maximum precipitation at most stations.

The majority of previous studies on the spatio-temporal patterns of precipitation in the Huai River Basin were based on sparsely distributed climate observations (Shi et al., 2013). However, observations of sufficient spatial and temporal resolution are crucial to the detection of patterns in climatic and hydrological series, especially in the Huai River 
Basin which is characterized by large spatio-temporal variability in precipitation due to its location in the climatic transition zone. To the best knowledge of the authors, this study uses the most comprehensive, long-term, and high quality data sets covering 134 rainfall stations from 1961 to 2013 for the entire basin. This study aims to (1) study the spatio-temporal characteristics of the occurrence of dry and wet periods defined by SPI, (2) detect both the annual and seasonal trends in SPI series using the Mann-Kendall test, and (3) identify the potential transition points in the annual and seasonal SPI series in the Huai River Basin.

\section{Materials and methods}

\subsection{Study area and data}

Located in eastern China between the Yangtze and Yellow River Basins, the Huai River Basin $\left(111^{\circ} 55^{\prime}-121^{\circ} 25^{\prime} \mathrm{E}\right.$ and $\left.30^{\circ} 55^{\prime}-36^{\circ} 36^{\prime} \mathrm{N}\right)$ drains a total area of $270,000 \mathrm{~km}^{2}$ with a population of 165 million. It is one of most densely populated regions in China, with a population density nearly 5 times the nation's average. The basin's western, southern, and northeastern parts are mountainous and hilly regions, which account for around one third of the basin's total area. The remaining of the basin is mostly alluvial plains, depressions, and lakes.

There are two water systems in the Huai River Basin, namely the Huai and the Yi-Shu-Si river systems. Originating from the Tongbai Mountain in Henan province, the Huai River flows eastward for more than $1000 \mathrm{~km}$ across Henan, Anhui, and Jiangsu provinces. The Yi-Shu-Si river system is located on the paleo-floodplain of the Yellow River. It originates from the Yimeng Mountain in Shandong province, and flows through Shandong and Jiangsu province before joining the Huai river system at the Hongze Lake. The entire Huai River Basin is divided into four water resource regions (WRRs), namely the Upper Huai River Basin, the Middle Huai River Basin, the Yi-Shu-Si River Basin, and the Lower Huai River Basin (Fig. 1).

The Huai River Basin is located in the climatic transition zone from north to south with four distinct seasons. It is under the influence of diverse weather systems including the westerly trough and cold vortex from the north and the tropical cyclone and easterly wave from the tropical region, as well as the local Jiang-Huai shear line and cyclone. Its annual average temperature ranges from 13.2 to $15.7^{\circ} \mathrm{C}$, evaporation from 900 to $1500 \mathrm{~mm}$, relative humidity from 66 to $81 \%$, and wind speed from 1.3 to $3.5 \mathrm{~m} / \mathrm{s}$. On average, the basin has a total of 200 to 240 frost free days, and 1990 to 2650 hours 
of sunshine in a year.

The average annual precipitation in the Huai River Basin is around $850 \mathrm{~mm}$, with more than 50 percent occurring in the flooding season from June to September. There are considerably large spatial and temporal variabilities in the basin's precipitation distribution. At some stations, the observed maximum annual rainfall could be four times more than the minimum amount. Meanwhile, annual precipitation could be more than $1400 \mathrm{~mm}$ in its southern mountainous region, compared to the range of 1000-1200 $\mathrm{mm}$ in its western mountainous region and $600-700 \mathrm{~mm}$ in its northern region.

The daily precipitation data at 134 stations in the Huai River Basin (Fig. 1) for the period 1961-2013 were obtained from the Meteorological Information Center of the Huai River Basin Commission. The data quality control was performed by the National Meteorological Information Center (NMIC) of the China Meteorological Administration (CMA). The NMIC checked the homogenization of the data using the departure accumulation method. The daily rainfall data at the 134 stations are all complete without any missing record.

\subsection{Method}

\subsubsection{Calculation of the SPI}

The SPI is used to investigate the spatial and temporal variations of the dryness/wetness in the Huai River Basin. The SPI is a widely used drought index calculated on the basis of the probability of the occurrence of certain amount of precipitation over multiple time scales (e.g. 1, 3, 6, 9, 12, and 24 months). To compute SPI, historic rainfall data at each station are fitted to a gamma probability distribution function as follows (McKee et al., 1993):

$$
\begin{aligned}
g(x) & =\frac{1}{\beta^{\alpha} \Gamma(\alpha)} x^{\alpha-1} e^{-x / \beta} \quad(x>0) \\
\Gamma(\alpha) & =\sum_{0}^{\infty} x^{\alpha-1} e^{-x} d x
\end{aligned}
$$

Where $x$ is the amount of precipitation $(\mathrm{mm})$ at certain time scale, $\alpha$ is the shape parameter, $\beta$ is the scale parameter, and $\Gamma(\alpha)$ defines the gamma function. Maximum likelihood method is used to estimate the shape parameter $\alpha$ and the scale parameter $\beta$.

The cumulative probability function of the precipitation distribution is given by

$$
G(x)=\int_{0}^{x} g(x) d x=\frac{1}{\beta^{\alpha} \Gamma(\alpha)} \int_{0}^{x} x^{\alpha-1} e^{-x / \beta} d x
$$


As the gamma function is undefined for $x=0$, the cumulative probability $H(x)$ is calculated as:

$$
H(x)=q+(1-q) G(x)
$$

Where $q$ is the probability of zero precipitation.

The cumulative probability $H(x)$ is then transformed to the standard normal random variable $\mathrm{Z}$ or the SPI value using the following approximation:

$$
\begin{aligned}
& Z=S P I=-\frac{t-\left(c_{0}+c_{1} t+c_{2} t^{2}\right)}{1+d_{1} t+d_{2} t^{2}+d_{3} t^{3}} \quad 0<H(x) \leq 0.5 \\
& Z=S P I=\frac{t-\left(c_{0}+c_{1} t+c_{2} t^{2}\right)}{1+d_{1} t+d_{2} t^{2}+d_{3} t^{3}} \quad 0.5<H(x) \leq 1
\end{aligned}
$$

where

$$
\begin{array}{rr}
t=\sqrt{\ln \left[1 / H(x)^{2}\right]} & 0<H(x) \leq 0.5 \\
t=\sqrt{\ln \left[1 /(1-H(x))^{2}\right]} & 0.5<H(x) \leq 1 \\
c_{0}=2.515517, c_{1}=0.802853, c_{2}=0.010328, d_{1}=1.432788, d_{2}=0.189269, \text { and }
\end{array}
$$
$d_{3}=0.001308$.

Classifications of the severity of dry and wet conditions based on the SPI values are listed in Table 1.

\subsubsection{Mann-Kendall (M-K) test}

The nonparametric Mann-Kendall test is a widely used non-parametric test for detecting trends in hydrological and meteorological time series (Tabari et al., 2011). For a time series of $n$ observations $\left(x_{1}, x_{2}, \ldots, x_{n}\right)$, the M-K test statistic $S$ is computed as follows:

$$
S=\sum_{i=1}^{n-1} \sum_{j=i+1}^{n} \operatorname{sgn}\left(x_{j}-x_{i}\right)
$$

Where

$$
\operatorname{sgn}\left(x_{j}-x_{i}\right)= \begin{cases}1 & x_{j}>x_{i} \\ 0 & x_{j}=x_{i} \\ -1 & x_{j}<x_{i}\end{cases}
$$

Mann (1945) and Kendall (1975) have documented that when $\mathrm{n} \geq 8$, the statistic $S$ is approximately normally distributed with zero mean and the following variance: 


$$
\operatorname{Var}(S)=\frac{n(n-1)(2 n+5)-\sum_{\mathrm{k}=1}^{\mathrm{m}} t_{k}\left(t_{k}-1\right)\left(2 t_{k}+5\right)}{18}
$$

Where $m$ is the number of tied groups, and $t_{k}$ denotes the number of ties of extent $k$. The standardized M-K test statistic $Z$ is then calculated to test the significance of the temporal trend at the desired significance level $\alpha$ :

$$
Z=\left\{\begin{array}{cc}
\frac{S-1}{\sqrt{\operatorname{Var}(S)}} & S>0 \\
0 & S=0 \\
\frac{S+1}{\sqrt{\operatorname{Var}(S)}} & S<0
\end{array}\right.
$$

The standardized M-K statistic $Z$ follows the standard normal distribution with a mean of 0 and variance of 1 . If $|Z|>Z_{1-\alpha / 2}$, a significant trend is accepted to exist in the time series.

\subsubsection{Pettitt test}

The non-parametric Pettitt test (Pettitt, 1979) was used to identify the significant change point in the SPI series. Pettitt test is a rank-based and distribution-free test for detecting a significant change in the mean of a time series when the exact time of the change is unknown (Zhang and Lu, 2009). A time series of $T$ observations $\left(x_{1}, x_{2}, \ldots, x_{T}\right)$ is divided into two groups: $x_{1}, x_{2}, \ldots, x_{t}$ and $x_{t+1}, x_{t+2}, \ldots, x_{T}$. A statistical index $U_{t, T}$ is defined as follows:

$$
U_{t, \mathrm{~T}}=\sum_{i=1}^{t} \sum_{j=t+1}^{\mathrm{T}} \operatorname{sgn}\left(x_{i}-x_{j}\right) \quad 1 \leq t<\mathrm{T}
$$

The most probable change point is found at:

$$
K_{t}=\max \left|U_{t, \mathrm{~T}}\right|
$$

The significance probability $p$ associated with $K_{t}$ is:

$$
p=2 \exp \left(\frac{-6 K_{t}^{2}}{T^{3}+T^{2}}\right)
$$

If $p<\alpha, x_{t}$ is accepted as a significant change point at the significance level $\alpha$.

\subsubsection{Correction of serial correlation}

Both the M-K test and Pettitt test may not be robust due to the potential serial correlation existing in the time series. To avoid the influence of serial correlation on the significance of their test statistics, the following steps are adopted when conducting the 
M-K test and Pettitt test on the SPI time series (Sayemuzzaman and Jha, 2014):

1) Compute the lag-1 serial correlation coefficient $\left(r_{1}\right)$ of the SPI time series $\left(x_{1}, x_{2}, \ldots, x_{n}\right)$ as:

$$
r_{1}=\frac{\frac{1}{n-1} \sum_{i=1}^{n-1}\left(x_{i}-\bar{x}\right) \cdot\left(x_{i+1}-\bar{x}\right)}{\frac{1}{n} \sum_{i=1}^{n}\left(x_{i}-\bar{x}\right)^{2}}
$$

Where $\bar{x}$ is the mean of the SPI time series.

2) Compute the confidence interval of $r_{1}$ at the $5 \%$ significance level as:

$$
\left[\frac{-1-1.96 \sqrt{n-2}}{n-1}, \frac{-1+1.96 \sqrt{n-2}}{n-1}\right]
$$

If $r_{1}$ falls within the confidence interval, the SPI time series is assumed to contain independent observations, and the $\mathrm{M}-\mathrm{K}$ test and Pettitt test are applied directly. Otherwise, the time series contains significant serial correlation, and the M-K test and Pettitt test are applied to the pre-whitened series instead, which is calculated as $\left(x_{2}-r_{1} x_{1}, x_{3}-r_{1} x_{2}, \ldots, x_{n}-r_{1} x_{n-1}\right)$.

\section{Results and discussion}

\subsection{Precipitation distribution}

Between 1961 and 2013, the average amount of annual precipitation in the Huai River Basin was $857 \mathrm{~mm}$ with a standard deviation of $148 \mathrm{~mm}$. The largest amount of annual precipitation was $1299 \mathrm{~mm}$ in 2003, more than twice the lowest amount of 519 mm in 1966. Summer (JJA) had the largest amount of precipitation, accounting for $37.0 \%$ to $70.4 \%$ of the annual total precipitation during the period. Precipitation in both autumn (SON) and spring (MAM) accounted for approximately $19 \%$ of the annual total precipitation. Winter (DJF) had the least amount of precipitation, accounting for around $7 \%$ of the annual total precipitation (Fig. 2).

There was substantial variation in precipitation across the four water resource regions in the Huai River Basin. Average annual precipitation was the largest (1023 mm) in the Upper Huai River Basin, followed by the Lower Huai River Basin (995 mm), the Middle Huai River Basin (839 mm), and the Yi-Shu-Si Basin (777 mm). Similarly, the Upper Huai River Basin exhibited the largest variability in annual precipitation with a standard deviation of $227 \mathrm{~mm}$, followed by the Lower Huai River Basin (213 mm), the Middle Huai River Basin (152 mm), and the Yi-Shu-Si Basin (150 mm) (Fig. 3). 
Seasonally, the four water resource regions exhibited a similar pattern in precipitation distribution with the largest share in summer and the smallest in winter. However, the actual seasonal proportions differed among the four regions. On the average, spring precipitation accounted for $23.9 \%$ of the annual total in the Upper Huai River Basin, around 20\% in the Middle and Lower Huai River Basin, and 16.2\% in the Yi-Shu-Si Basin. Summer precipitation accounted for $48.4 \%$ of the annual total in the Upper Huai River Basin, slightly over 50\% in the Middle and Lower Huai River Basin, and $60.9 \%$ in the Yi-Shu-Si Basin. Autumn precipitation accounted for around 19\% of annual total in all four regions. Winter precipitation accounted for $4.8 \%$ in the Yi-Shu-Si Basin, and 7 to $9 \%$ in the other three regions (Fig. 3).

\subsection{Frequency of dry and wet years}

Annual SPI values from 1961 to 2013 were calculated for the 134 rain stations in the Huai River Basin. Based on the threshold values in Table 1, the number of dry (i.e. $\mathrm{SPI} \leq-1.0$ ) and wet years (i.e. $\mathrm{SPI} \geq 1.0$ ) that each rain station has experienced was counted. The results showed that the Huai River Basin was prone to hydrological extremes in terms of both drought and flood during the period. Over the period of 53 years, 24 stations went through either dry or wet conditions for 20 years or more, and 102 additional stations for 15 years or more.

Individually, each station experienced a range of 6 to 12 dry years and 5 to 13 wet years, some of which were severe. Nearly all stations have experienced both severely wet and dry conditions. Twenty one stations have experienced severely wet conditions for 5 or more years, including 1 in the Upper Huai River Basin, 13 in the Middle Huai River Basin, 7 in the Yi-Shu-Si Basin, and none in the Lower Huai River Basin. Meanwhile, 39 stations have experienced severely dry conditions for 5 or more years, including 5 in the Upper Huai River Basin, 19 in the Middle Huai River Basin, 9 in the Yi-Shu-Si Basin, and 6 in the Lower Huai River Basin (Fig. 4).

\subsection{Trend analysis of annual and seasonal SPI series}

The $\mathrm{M}-\mathrm{K}$ test was employed to detect the temporal trends of SPI at the 134 rain stations both annually and seasonally. The 3-month SPI values (SPI-3) at February, May, August, and November were used in the seasonal trend analysis for winter, spring, summer, and autumn, respectively.

Annually, the SPI values (SPI-12) exhibited a decreasing trend at 86 stations and an increasing trend at 47 stations. None of the increasing trend is significant, while the 
decreasing trend is significant at one station each in the Upper Huai River Basin and Yi-Shu-Si Basin at 95\% confidence level and one other station in the Upper Huai River Basin at $90 \%$ level. Regionally, all except one station showed a decreasing trend in annual SPI in the Upper Huai River Basin. In the Yi-Shu-Si and Lower Huai River Basins, more than $69 \%$ of the stations showed a decreasing trend, and the percentage dropped to 55\% in the Middle Huai River Basin (Fig. 5).

The seasonal SPI-3 values exhibited distinctly different patterns of change during the four seasons. In general, a largely dominating drying tendency could be observed in spring and autumn, and the opposite in summer and winter. In spring, more than 90 stations showed a decreasing trend, although none of them was significant. All of the stations in the Upper and Lower Huai River Basins exhibited a drying trend in spring. In contrast, more than $70 \%$ of stations exhibited a wetting trend in the Yi-Shu-Si Basin. In addition, 15 stations also exhibited a wetting trend in the Middle Huai River Basin, most of which were clustered in its northern part. The drying trend was more evident in autumn, with 126 stations showing a decreasing trend in SPI-3 and 31 stations significant at $90 \%$ confidence level. Most of the stations with a significant drying trend were in the western part of the Huai River Basin. In the Upper Huai River Basin, for example, 11 out of 12 stations exhibited a significant drying trend (Fig. 6).

In summer, 96 stations have exhibited an increasing trend in SPI-3with 7 stations being significant. More than $75 \%$ of the stations showed a wetting summer trend in all four water resource regions except less than $50 \%$ in the Yi-Shu-Si basin. The wetting trend was more apparent in winter with 126 stations showing an increasing trend in SPI-3, including 10 stations significant at 90\% confidence level, 11 stations at $95 \%$ level, and 23 stations at $99 \%$ level. Most of the stations with the significant wetting winter trend were clustered in the northern part of the Yi-Shu-Si Basin and the south central and southeastern part of the Huai River Basin (Fig. 6).

There have been a number of studies on the spatio-temporal patterns of annual and seasonal precipitation in the Huai River Basin. It is worth noting that some results may not be directly comparable to this study due to the different length of time series and number of rainfall stations used. Yuan et al. (2012) calculated the average annual precipitation of the Huai River Basin between 1961 and 2010 based on the Inverse Distance Weighting of precipitation data at 48 stations. They found that the annual precipitation exhibited a slight decreasing trend of $-0.2 \mathrm{~mm} / \mathrm{year}$. Based on the spatial interpolation of the slope of the linear regression against years at each individual station, 
they found a decreasing trend of annual precipitation in the Yi-Shu-Si Basin, and an increasing trend at some parts of the other three water resource regions. Different from their results, our analysis results indicated that the majority of the stations in the Upper and Lower Huai River Basins exhibited a decreasing trend in the annual SPI. Xia et al. (2012) and Du et al. (2014) analyzed the annual maximum precipitation series at around 30 meteorological stations in the Huai River Basin. They both observed a positive trend at more than $60 \%$ of the stations, without any trend being significant. In the Huai River Basin, annual maximum precipitation generally occurred in the summer. Consistent with their findings, we have detected an increasing trend in summer SPI at more than $70 \%$ of the stations, although we did detect a significant trend at some stations. Shi et al. (2013) analyzed the trends in precipitation in the upstream Shaying River catchment of the Huai River Basin based on precipitation data at 38 rainfall stations from 1951 to 2010. They observed mostly negative trends in spring and autumn precipitation series and positive trends in the summer and winter series, which is consistent with our findings. However, different from our findings, they detected more significant trends in summer than the other seasons. This is mainly because the upstream region exhibited different patterns of precipitation change from the other regions of the Huai River Basin.

\subsection{Shifts in annual and seasonal SPI series}

The non-parametric Pettitt test was used to analyze both the annual and seasonal SPI series for all 134 stations to detect the transition points when significant change in precipitation may have occurred. No point of abrupt change has been detected in the annual and spring SPI series. Significant points of transition have been detected at 17 stations in the autumn SPI series and 37 stations in the winter SPI series at $90 \%$ confidence level (Fig. 7). The distribution of these stations was consistent with those exhibiting significant temporal trends of drying in autumn or wetting in winter (Fig. 6).

The significant transition points in the autumn and winter SPI series were relatively consistent across the Huai River Basin. The 17 significant transition points for drying autumn all fell between 1987 and 1991, while those for wetting winter between 1984 and 1988. In addition, there were two stations in the middle Huai River Basin with abrupt increase in their summer SPI series at $90 \%$ confidence level, whose shifting years were estimated to be 2000 and 1994, respectively.

Since the identified significant transition years were largely in the middle to late 1980s, two sub-periods of equal length were selected for comparison of the occurrence 
of extreme events in the Huai River Basin: 1961 to 1984 and 1990 to 2013. The average number of dry and wet years in each of the four water resource regions was calculated for both sub-periods (Fig. 8). The two-sample $t$ test results indicated a significant increase in the average number of extremely wet years in all four water resource regions except the Upper Huai River Basin. The average number of extremely wet years in the Upper Huai River Basin doubled from 0.7 to 1.5 years. The statistical insignificance in the region could be due to its relatively small number of 12 rainfall stations available. Unlike extremely wet events, there has been no significant change in the average number of moderately wet years except a significant increase in the Lower Huai River Basin. As to dry events, there was no significant change in the average length of extremely dry years, except a significant decrease in the Middle Huai River Basin. There was also a significant increase in the average number of moderately dry years in the Upper and Middle Huai River Basins, and no significant change in the other two regions.

\section{Conclusion}

Due to its flexibility in temporal scale and capacity to represent precipitation anomaly, SPI is a valuable tool for studying the spatiotemporal pattern of dry and wet conditions in a region. Based on the daily precipitation data at 134 stations between 1961 and 2013, this paper calculated and analyzed the annual and seasonal SPI series across the Huai River Basin. Study results have indicated that the Huai River Basin was prone to both flood and drought during the study period (Fig. 4). Annually, although there has been a mixture of increasing and decreasing trends in the SPI series, none of them was significant except three stations with a significant decreasing trend (Fig. 5). Seasonally, there has been a prevailing drying trend in spring and autumn, and wetting trend in summer and winter. The trends in spring and summer have been mostly insignificant, while those in autumn and winter significant at more than 30 stations (Fig. 6). The significant transition points in the autumn and winter SPI series have been mostly in the middle to late 1980's. Comparison of the average number of dry and wet years between the two sub-periods of 1961-1984 and 1990-2013 indicated a significant increase in the occurrence of severely wet years across much of the Huai River Basin since 1990 (Fig. 7). Compared to previous studies, the use of much denser rainfall stations and longer time series up to 2013 has allowed to gain more insights into the spatial-temporal patterns of change in precipitation in the Huai River Basin.

Our analysis of the annual and seasonal SPI series of the Huai River Basin has 
indicated that some significant changes have already occurred in the dry and wet conditions of the basin, which could have profound impacts on the agriculture and water resources management of the region. For example, food production in the basin could be adversely affected by the decreasing water availability in the essential crop growing seasons of autumn and spring in view of the drying SPI trend in the two seasons. Meanwhile, the increasing SPI trend in the summer could imply more flooding events and the possible needs of enhanced measures for flood prevention and mitigation.

Understanding the physical factors driving the changes in rainfall and developing feasible adaptation strategies are in urgent need to achieving the sustainable use of the water resources in the Huai River Basin. The influences of El Niño-Southern Oscillation (ENSO) and the Pacific Decadal Oscillation (PDO) on precipitation over China are found to have clear seasonal and monthly characteristics (Ouyang et al, 2014). There is however a lack of in-depth study on the linkages between ENSO/PDO and the variations in annual and seasonal precipitation in the Huai River Basin. Due to its location in the north-south climatic transition zone, it will be challenging but very important to study the attribution of the precipitation trends in the Huai River Basin and investigate the relationships between its precipitation variability and the inter-annual and multi-decadal modes of climatic variability such as ENSO as well as anthropogenic climate change. An improved understanding of the relationships could not only help to improve the understanding in precipitation variability, but also to enhance the capacity in medium-range forecast of precipitation for this region.

\section{Acknowledgement}

The authors gratefully acknowledge the financial support provided by Chinese Natural Science Foundation (41201191), Chinese Ministry of Education New Faculty Fund (20120071120034), and Fudan University Tyndall Center Project (FTC98503B04).

\section{References}

Bazrafshan, J., Hejabi, S., Rahimi, J., 2014. Drought monitoring using the multivariate standardized precipitation index (MSPI). Water Resour. Manag. 28, 1045-1060.

Cheo, A. E., Voigt, H. J., Mbua, R. L., 2013. Vulnerability of water resources in northern Cameroon in the context of climate change. Environ. Earth Sci. 70, 1211-1217.

Dhakar, R., Sehgal, V.K., Pradhan, S., 2013. Study on inter-seasonal and intra-seasonal relationships of meteorological and agricultural drought indices in the Rajasthan State of India. J. Arid. Environ. 97, 108-119. 
Di Lena, B., Vergni, L., Antenucci, F., Todisco, F., Mannocchi, F., 2014. Analysis of drought in the region of Abruzzo (Central Italy) by the Standardized Precipitation Index. Theor. Appl. Climatol. 115, 41-52.

Du, H., Xia, J., Zeng, S.D., 2014. Regional frequency analysis of extreme precipitation and its spatio-temporal characteristics in the Huai River Basin, China. Nat. Hazards. $70,195-215$.

Du, J., Fang, J., Xu, W., Shi, P.J., 2013. Analysis of dry/wet conditions using the standardized precipitation index and its potential usefulness for drought/flood monitoring in Hunan Province, China. Stoch. Environ. Res. Risk Assess. 27, 377-387.

Dutra, E., Di Giuseppe, F., Wetterhall, F., Pappenberger, F., 2013. Seasonal forecasts of droughts in African basins using the Standardized Precipitation Index. Hydrol. Earth Syst. Sci. 17, 2359-2373.

Feng, J., Yan, D. H., Li, C. Z., 2013. Evolutionary trends of drought under climate change in the Heihe River basin, Northwest China. J. Food Agric. Environ. 11, 1025-1031.

Fischer, T., Gemmer, M., Su, B., Scholten, T., 2013. Hydrological long-term dry and wet periods in the Xijiang River basin, South China. Hydrol. Earth Syst. Sci. 17, 135-148.

Ford, T., Labosier, C.F., 2014. Spatial patterns of drought persistence in the Southeastern United States. Int. J. Climatol. 34, 2229-2240.

Ganguli, P., Reddy, M.J., 2014. Evaluation of trends and multivariate frequency analysis of droughts in three meteorological subdivisions of western India. Int. J. Climatol. 34, 911-928.

Gocic, M., Trajkovic, S., 2013. Analysis of precipitation and drought data in Serbia over the period 1980-2010. J. Hydrol. 494, 32-42.

Gocic, M., Trajkovic, S., 2014. Spatiotemporal characteristics of drought in Serbia. J. Hydrol. 510, 110-123.

Ye, J., He, Y., Pappenberger, F., Cloke, H.L., Manful, D.Y., Li, Z., 2014, Evaluation of ECMWF medium-range ensemble forecasts of precipitation for river basins. Q.J.R. Meteorol. Soc., 140: 1615-1628.

Huang, J., Sun, S.L., Xue, Y., Li, J.J., Zhang, J.C., 2014. Spatial and Temporal Variability of Precipitation and Dryness/Wetness During 1961-2008 in Sichuan Province, West China. Water Resour. Manag. 28, 1655-1670. 
Karavitis, C. A., Chortaria, C., Alexandris, S., Vasilakou, C. G., Tsesmelis, D. E., 2012. Development of the standardised precipitation index for Greece. Urban Water J. 9, 401-417.

Kendall, M. G., 1975. Rank Correlation Measures. Charles Griffin, London.

Li, B. Su, H.B., Chen, F., Li, S.G., Tian, J., Qin, Y.C., Zhang, R.H., Chen, S.H., Yang, Y.M., Rong, Y., 2013. The changing pattern of droughts in the Lancang River Basin during 1960-2005. Theor. Appl. Climatol. 111, 401-415.

Liu, X.C., Xu, Z.X., Yu, R.H., 2012. Spatiotemporal variability of drought and the potential climatological driving factors in the Liao River basin. Hydrol. Process. 26, $1-14$.

Mann, H. B., 1945. Non-parametric tests against trend. Econometrica. 13, 245-259.

McKee, T., Doesken, N., Kleist, J., 1993. The relationship of drought frequency and duration to time scales. Preprints Eighth Conf on Applied Climatology, Am. Meteor. Soc, Boston, Anaheim, CA, pp. 179-184.

Mishra, A.K., Singh, V.P., 2011. Drought modeling - A review. J. Hydrol. 403, 157-175.

Oguntunde, P.G., Lischeid, G., Abiodun, B.J., Dietrich, O., 2014. Analysis of spatial and temporal patterns in onset, cessation and length of growing season in Nigeria. Agric. For. Meteorol. 194, 77-87.

Ouyang, R., Liu, W., Fu, G., Liu, C., Hu, L., Wang, H., 2014. Linkages between ENSO/PDO signals and precipitation, streamflow in China during the last 100 years, Hydrol. Earth Syst. Sci., 18, 3651-3661.

Parry, M., Canziani, O., Palutikof, J., Linden, P.v.d., Hanson, C., 2007. Climate Change 2007: Impacts, Adaptation and Vulnerability. Contribution of Working Group II to the Fourth Assessment Report of the Intergovernmental Panel on Climate Change. Cambridge University Press, Cambridge, UK, pp. 982.

Pettitt, A.N., 1979. A non-parametric approach to the change-point problem. Appl. Statistics. 28, 126-135.

Raziei, T., Bordi, I., Pereira, L.S., Corte-Real, J., Santos, J.A., 2012. Relationship between daily atmospheric circulation types and winter dry/wet spells in western Iran. Int. J. Climatol. 32, 1056-1068.

Sayemuzzaman, M., Jha, M. K., 2014. Seasonal and annual precipitation time series trend analysis in North Carolina, United States. Atmospheric Research 137, 183-194. 
Shi, P., Ma, X., Chen, X., Qu, S., Zhang, Z., 2013. Analysis of variation trends in precipitation in an upstream catchment of Huai River. Math. Probl. Eng. 2013, http://dx.doi.org/10.1155/2013/929383.

Shi, P., Qiao, X.Y., Chen, X., Zhou, M., Qu, S.M., Ma, X.X., Zhang, Z.C., 2014. Spatial distribution and temporal trends in daily and monthly precipitation concentration indices in the upper reaches of the Huai River, China. Stoch. Environ. Res. Risk Assess. 28, 201-212.

Spinoni, J., Naumann, G., Carrao, H., Barbosa, P., Vogt, J., 2014. World drought frequency, duration, and severity for 1951-2010. Int. J. Climatol. 34, 2792-2804.

Tabari, H., Abghari, H., Talaee, P.H., 2012. Temporal trends and spatial characteristics of drought and rainfall in arid and semiarid regions of Iran. Hydrol. Process. 26, 3351-3361.

Tabari, H., Somee, B.S., Zadeh, M.R., 2011. Testing for long-term trends in climatic variables in Iran. Atmospheric Research. 100, 132-140.

Tosic, I., Unkasevic, M., 2014. Analysis of wet and dry periods in Serbia. Int. J. Climatol. 34, 1357-1368.

Wu, Y.X., Yao, H.M., Wang, G.X., Shen, G.C., Shi, R., Hou, B.D., 2011. Analysis on characteristics of extreme drought and flood events in the Huai River Basin (Chinese). Hydro-Science and Engineering.149-153.

Xia, J., She, D., Zhang, Y., Du, H., 2012. Spatio-temporal trend and statistical distribution of extreme precipitation events in Huaihe River Basin during 1960-2009. J. Geogr. Sci. 22, 195-208.

Xie, H., Ringler, C., Zhu, T.J., Waqas, A., 2013. Droughts in Pakistan: A spatiotemporal variability analysis using the Standardized Precipitation Index. Water Int. 38, 620-631.

Yuan, Z., Yang, Z., Zheng, X., Yuan, Y., 2012. Spatial and Temporal Variations of Precipitation in Huai River Basin in the Recent 50 Years (Chinese). South-to-North Water Diversion and Water Science \& Technology. 10, 98-103.

Zhang, Q., Li, J.F., Singh, V.P., Bai, Y.G., 2012. SPI-based evaluation of drought events in Xinjiang, China. Nat. Hazards. 64, 481-492.

Zhang, Q., Xu, C.Y., Zhang, Z.X., 2009. Observed changes of drought/wetness episodes in the Pearl River basin, China, using the standardized precipitation index and aridity index. Theor. Appl. Climatol. 98, 89-99.

Zhang, S., Lu, X.X., 2009. Hydrological responses to precipitation variation and diverse 
human activities in a mountainous tributary of the lower Xijiang, China. Catena. 77, 130-142.

Zhao, G.J., Mu, X.M., Hormann, G., Fohrer, N., Xiong, M., Su, B.D., Li, X.C., 2012. Spatial patterns and temporal variability of dryness/wetness in the Yangtze River Basin, China. Quat. Int. 282, 5-13.

Zin, W.Z.W., Jemain, A.A., Ibrahim, K., 2013. Analysis of drought condition and risk in Peninsular Malaysia using Standardised Precipitation Index. Theor. Appl. Climatol. 111, 559-568. 


\section{Figure Captions}

Fig. 1. Study region. The four water resources regions of the Huai River Basin are indicated in the main panel. The solid circles represent the 134 rainfall stations.

Fig. 2. Annual and seasonal precipitation in the Huai River Basin.

Fig. 3. Annual and seasonal precipitation in the four water resource regions of the Huai River Basin.

Fig. 4. Number of severely (a) wet and (b) dry years in the Huai River Basin between 1961 and 2013.

Fig. 5. The annual SPI trends of the 134 rain stations in the Huai River Basin between 1961 and 2013. Up and down arrows represent wetting and drying trends, respectively. Red arrows indicate significant trends at $90 \%$ confidence level.

Fig. 6. The seasonal SPI trends of the 134 rain stations in the Huai River Basin between 1961 and 2013. Up and down arrows represent wetting and drying trends, respectively. Red arrows indicate significant trends at 90\% confidence level. (a) Spring (MAM); (b) Summer (JJA); (c) Autumn (SON); (d) Winter (DJF).

Fig. 7. Distribution of transition years in the seasonal SPI series in the Huai River Basin between 1961and 2013. (a) Autumn (SON); (b) Winter (DJF).

Fig. 8. Comparison of the average number of dry and wet years across the water resource regions: 1961-1984 and 1990-2013. 